\title{
Improved DPC Strategy of Grid-connected Inverters under Unbalanced and Harmonic Grid Conditions
}

\author{
Yongbo Shen* and Heng Nian**
}

\begin{abstract}
This paper presents an improved direct power control (DPC) strategy for gridconnected voltage source inverter (VSI) under unbalanced and harmonic grid voltage conditions. Based on the mathematic model of VSI with the negative sequence, 5th and 7th harmonic voltage components consideration, a PI controller is used in the proposed DPC strategy to achieve the average output power regulation. Furthermore, vector PI controller with the resonant frequency tuned at the two times and six times grid fundamental frequency is adopted to regulate both negative and harmonic components, and then two alternative targets of the balanced/sinusoidal current and smooth active/reactive output power can be achieved. Finally, simulation results based on MATLAB validate the availability of the proposed DPC strategy.
\end{abstract}

Keywords: Direct power control, Grid-connected voltage source inverter, Unbalanced and harmonic grid, Vector PI controller

\section{Introduction}

Grid-connected voltage source inverter (VSI) has gained the increasing popularity in both the renewable power generation systems and the electric power systems, including wind power generation systems, high voltage direct current systems, etc., due to the advantage of controllable power factor and sinusoidal current output [1]. Usually, two main control strategies, i.e., voltage or flux oriented vector control (VC) [2] and direct power control (DPC) [3], have been well investigated in VSI under the ideal grid condition. However, the unbalanced and harmonic voltage distortion always appears both in transmission and distribution grid, which will deteriorate the operation performance of VSI if the negative sequence and the harmonic components of grid voltage are not considered in the control system [4]-[6]. Thus, it is necessary to investigate the control strategy of VSI to enhance the quality of power or current injected to the grid during unbalanced and harmonic voltage disturbances.

Up to now, the investigation on the VSI during the unbalanced and harmonic grid voltage condition was mainly implemented by VC strategy. [7]-[8] used the dual current regulator on the positive and negative synchronous

\footnotetext{
* Dept. of Electrical Engineering, Zhejiang University, China. (yongboshen@gmail.com)

** Dept. of Electrical Engineering, Zhejiang University, China. (nianheng@zju.edu.cn)
}

Received 15 April 2014 ; Accepted 10 May 2014 reference frame to implement the stable sinusoidal current output under unbalanced grid voltage. In [9], the current controller consisting of a PI regulator and a dual-frequency resonant compensator was proposed to improve the operation capability of DFIG based wind turbine system under both unbalanced and distorted grid voltage conditions. However, the time delay and control error in VC is unavoidable due to the sequence decomposition of the voltage and current, and the current reference computation of the different control target is also complicated.

DPC has been considered as the preponderant scheme for VSI operation under the unbalanced and harmonic grid conditions, due to the advantages of simple implementation and fast dynamic response [10]. DPC can be classified into two categories, hysteresis controller based DPC (HC-DPC) [4]-[5] and space vector modulation based DPC (SVMDPC) [10]-[11]. Paper [12] proposed a modified predictive DPC in stationary reference frame to obtain the balanced and sinusoidal current under the unbalanced grid conditions. Generally, HC-DPC will lead to a variable switching frequency of converters, which will complicate the design of power filter. SVM-DPC can obtain the AC side current with the constant switching frequency, which is beneficial for the design of power filter [10]. However, up to now, it cannot be found the corresponding DPC strategy for VSI aimed at the stable operation under the unbalanced and harmonic grid.

In order to restrain the harmonic current components, the resonant controller has been applied to assure steady-state tracking and disturbance rejection for components pulsation 
at the specified frequency [10], [13]-[14]. Due to the super ior tracking capability of ac signal by using the pole-zero cancellation, the VPI regulator is introduced to replace conventional PIR regulator to enhance the operation stability of VSI [15].

This paper presents an integrated control strategy for VSI under unbalanced and distorted grid voltage based on the SVM-DPC strategy, in which two alternative control targets, the balanced and sinusoidal current, smooth active and reactive power output, are proposed to enhance the operation capability of VSI. The VPI controller tuned at the twice and sixth fundamental frequency is adopted to eliminate current or power oscillation. Finally, the simulation model is developed to validate the availability of the proposed DPC strategy.

\section{Improved DPC Strategy for VSI}

The circuit of grid-connected voltage-sourced inverters is shown in Fig. 1, in which $u_{\text {ga }}, u_{g b}, u_{g c}$ are the grid voltage, $i_{\text {ga }}, i_{g b}, i_{g c}$ are the grid current, $u_{\underline{\text { ca }}}, u_{c b}, u_{c c}$ are the AC side converter voltage, $L$ is the line inductance and $R$ is resistance, $V_{d c}$ is the direct voltage source. The mathematic model of inverter under positive fundamental synchronous frame can be expressed as,

$$
\left\{\begin{array}{l}
U_{g d}^{+}=R I_{g d}^{+}-\omega_{g} L I_{g q}^{+}+L \frac{d I_{g d}^{+}}{d t}+U_{c d}^{+} \\
U_{g q}^{+}=R I_{g q}^{+}+\omega_{g} L I_{g d}^{+}+L \frac{d I_{g q}^{+}}{d t}+U_{c q}^{+}
\end{array}\right.
$$

where the superscript + is in the positive $d-q$ reference frame, the subscript $\mathrm{g} d$ and $g q$ is the $\mathrm{d}-\mathrm{q}$ axis components of grid voltage and current in synchronous frame and the subscript $c d$ and $c q$ is the d-q axis components of converter voltage in synchronous frame.

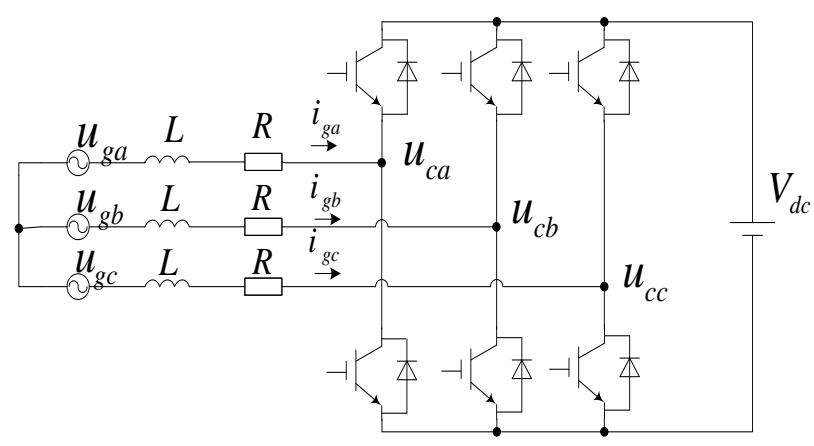

Fig. 1. VSI circuit
Fig. 2. depicts the equivalent circuit of the VSI. Thus, the flux linkages of VSI can be defined as [10], where the leakage flux and loss during the transmission is neglected.

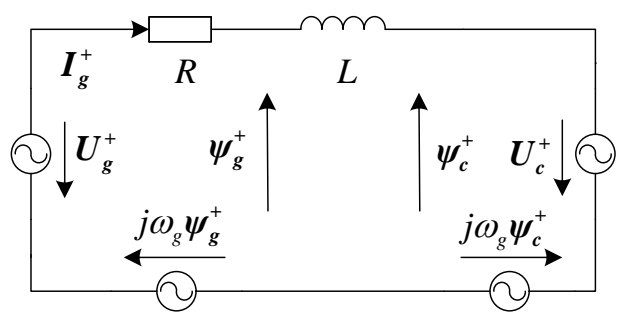

Fig. 2 VSI equivalent circuit

$$
\left\{\begin{array}{l}
\boldsymbol{\psi}_{g}^{+}=\int \boldsymbol{U}_{g}^{+} d t \\
\boldsymbol{\psi}_{c}^{+}=\int \boldsymbol{U}_{c}^{+} d t
\end{array}\right.
$$

where $\psi_{g}^{+}$is the grid flux vector, $\psi_{c}^{+}$is the VSI flux vector, $\boldsymbol{U}_{g}^{+}=U_{g d}^{+}+j U_{g q}^{+}$is the grid voltage vector, $\boldsymbol{U}_{c}^{+}=U$ ${ }_{c d}^{+}+j U_{c q}^{+}$is the inverter voltage vector and $\boldsymbol{I}_{g}^{+}$is the grid current vector.

According to the equivalent circuit in Fig.2, the relationships between the voltage current and flux are deduced as

$$
\begin{gathered}
\boldsymbol{U}_{g}^{+}=R \boldsymbol{I}_{g}^{+}+\frac{d \boldsymbol{\psi}_{g}^{+}}{d t}+j \omega_{g} \boldsymbol{\psi}_{g}^{+} \\
\boldsymbol{U}_{c}^{+}=\frac{d \boldsymbol{\psi}_{c}^{+}}{d t}+j \omega_{g} \boldsymbol{\psi}_{c}^{+} \\
\boldsymbol{U}_{g}^{+}=R \boldsymbol{I}_{g}^{+}+L \frac{d \boldsymbol{I}_{g}^{+}}{d t}+j \omega_{g}\left(\boldsymbol{\psi}_{g}^{+}-\boldsymbol{\psi}_{c}^{+}\right)+\boldsymbol{U}_{c}^{+} \\
\boldsymbol{\psi}_{g}^{+}=L \boldsymbol{I}_{g}^{+}+\boldsymbol{\psi}_{c}^{+}
\end{gathered}
$$

Compared with $L, R$ is small enough to be neglected. Once the $d$-axis of the synchronous frame is fixed with the grid voltage vector, according to (3), the steady state grid voltage can be simplified as,

$$
\boldsymbol{U}_{g}^{+}=j \omega_{g} \psi_{g}^{+}=-\omega_{g} \psi_{g q}^{+}=U_{g d}^{+}
$$

Thus, the power of VSI can be calculated as,

$$
S_{g}=P_{g}+j Q_{g}=\frac{3}{2} \boldsymbol{U}_{g}^{+} \times \hat{\boldsymbol{I}_{g}^{+}}=\frac{3}{2} U_{g d}^{+} \times \frac{1}{L}\left(\hat{\boldsymbol{\psi}_{g}^{+}}-\hat{\boldsymbol{\psi}_{c}^{+}}\right)
$$

where $P_{g}$ is the grid active power, $Q_{g}$ is the grid reactive power. Substituting (7) into (8), the active and reactive power outputs are written as 


$$
\left\{\begin{array}{l}
P_{g}=-\frac{3}{2} \frac{U_{g d}^{+}}{L} \psi_{c d}^{+} \\
Q_{g}=\frac{3}{2} \frac{U_{g d}^{+}}{L}\left(\psi_{c q}^{+}+\frac{U_{g d}^{+}}{\omega_{g}}\right)
\end{array}\right.
$$

According to (9), the VSI output flux $\psi_{c}^{+}$and its differential $d \boldsymbol{\psi}_{c}^{+} / d t$ can be rewritten in terms of the active and reactive output power of VSI [10]. Substituting (9) into (3), the VSI output voltage can be expressed as,

$$
\left\{\begin{array}{l}
U_{c d}^{+}=-\frac{2}{3} \frac{L}{U_{g d}^{+}} \frac{d P_{g}}{d t}-\frac{2}{3} \frac{\omega_{g} L}{U_{g d}^{+}} Q_{g}+U_{g d}^{+} \\
U_{c q}^{+}=\frac{2}{3} \frac{L}{U_{g d}^{+}} \frac{d Q_{g}}{d t}-\frac{2}{3} \frac{\omega_{g} L}{U_{g d}^{+}} P_{g}
\end{array}\right.
$$

where $\omega_{g}$ is approximate to a constant. (10) is the control equation of direct power control of VSI.

According to [6], the instantaneous power of VSI under unbalanced and harmonic voltage grid conditions can be represented as,

$$
\begin{aligned}
& P_{g}+j Q_{g}=\frac{3}{2} \boldsymbol{U}_{g}^{+} \times \hat{\boldsymbol{I}_{g}^{+}}
\end{aligned}
$$

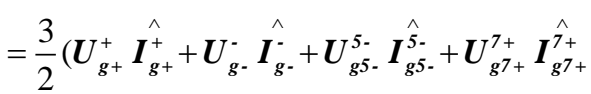

$$
\begin{aligned}
& +\boldsymbol{U}_{g_{+}}^{+} \hat{\boldsymbol{I}_{g_{-}}^{-}} e^{j 2 \omega_{g} t}+\boldsymbol{U}_{g_{-}}^{-} \hat{\boldsymbol{I}_{g_{+}}^{+}} e^{-j 2 \omega_{g} t}
\end{aligned}
$$

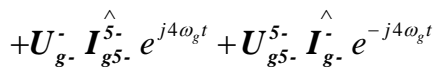

$$
\begin{aligned}
& +\boldsymbol{U}_{g+}^{+} \boldsymbol{I}_{g 5_{-}}^{\hat{\boldsymbol{s}_{-}}} e^{j 6 \omega_{g} t}+\boldsymbol{U}_{g+}^{+} \boldsymbol{I}_{g 7_{+}}^{\hat{7_{+}} e^{-j 6 \omega_{g} t}} \\
& +\boldsymbol{U}_{g 5_{-}}^{5-} \hat{\boldsymbol{I}_{g+}^{+}} e^{-j 6 \omega_{g} t}+\boldsymbol{U}_{g 7+}^{7+} \hat{\boldsymbol{I}_{g+}^{+}} e^{j 6 \omega_{g} t} \\
& +\boldsymbol{U}_{g \cdot}^{-} \hat{\boldsymbol{I}}_{g 7_{+}}^{\hat{\eta_{+}}} e^{-j 8 \omega_{g} t}+\boldsymbol{U}_{g 7+}^{7+} \hat{\boldsymbol{I}_{g \cdot}^{-}} e^{j 8 \omega_{g} t}
\end{aligned}
$$

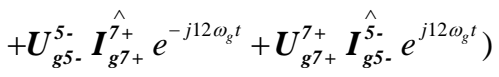

$$
\begin{aligned}
& \left\{\begin{array}{l}
P_{g}=P_{0}+P_{2}+P_{4}+P_{6}+P_{8}+P_{12} \\
Q_{g}=Q_{0}+Q_{2}+Q_{4}+Q_{6}+Q_{8}+Q_{12}
\end{array}\right.
\end{aligned}
$$

where $\boldsymbol{U}_{g^{+}}^{+}$and $\boldsymbol{I}_{g^{+}}^{+}$are the positive-sequence components in the synchronous $(d q)^{+}$coordinate. $\boldsymbol{U}_{g_{-}^{-}}^{-}$and $\boldsymbol{I}_{g_{-}}^{-}$are the negative sequence components in the synchronous $(d q)^{-}$

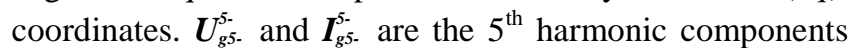
in the $(d q)^{5-}$ coordinates. $\boldsymbol{U}_{g 7+}^{7+}$ and $\boldsymbol{I}_{g 7+}^{7+}$ are the $7^{\text {th }}$ harmonic components in the $(d q)^{7+}$ coordinates. $P_{0}$ and $Q_{0}$ are the dc component of VSI power output. $P_{n}$ and $Q_{n}$ are the $\mathrm{n}(\mathrm{n}=2$, $4,6,8,12)$ times of grid frequency power pulsations. Compared with $\boldsymbol{I}_{g^{+}}^{+}, \boldsymbol{I}_{\boldsymbol{g}_{-}}, \boldsymbol{I}_{g^{5-}}^{5-}$ and $\boldsymbol{I}_{g^{\prime+}}^{7+}$ can be neglected. The main power pulsations will focus on $2^{\text {nd }}$ and $6^{\text {th }}$ grid frequency.
Thus, based on (10) and (12), the improved DPC scheme is proposed as showed in Fig. 3. The grid voltages $u_{g a b c}$ and currents $i_{g a b c}$ are transformed into $d q$ components by synchronous $(d q)^{+}$coordinates based on the PLL. The PLL block is designed to track the frequency and phase angle of grid voltage. The $d q$ components of grid voltages and currents are used to calculate the instantaneous power $P_{g}$ and $Q_{g}$ according to (13).

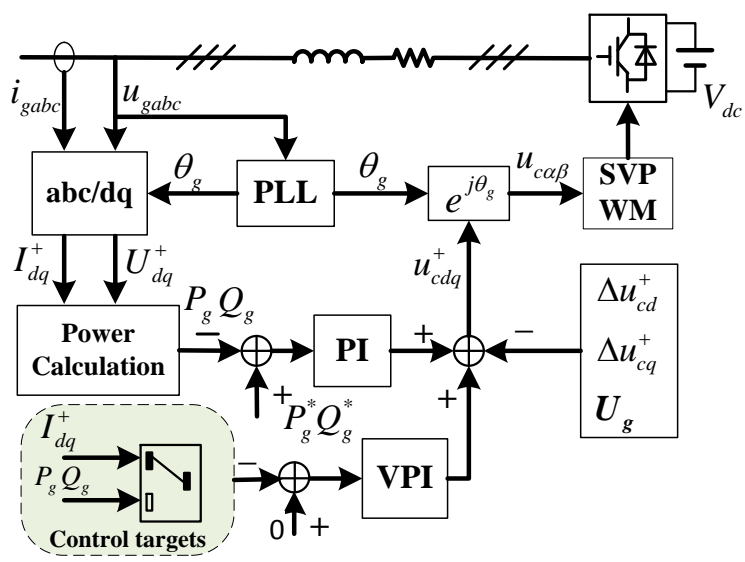

Fig. 3 Proposed DPC integrated control scheme

$$
\left\{\begin{array}{l}
P_{g}=\frac{3}{2}\left(U_{g d}^{+} I_{g d}^{+}+U_{g q}^{+} I_{g q}^{+}\right) \\
Q_{g}=\frac{3}{2}\left(U_{g q}^{+} I_{g d}^{+}-U_{g d}^{+} I_{g q}^{+}\right)
\end{array}\right.
$$

The active and reactive power reference $P_{g}^{*} \quad Q_{s}^{*}$ are given as constants. The PI controllers are applied to achieve the control of average power output. There are two separate control targets to be chosen. The first control target is to obtain balanced and sinusoidal current by selecting the $I_{d q}^{+}$ as the input signal of VPI controller, while the second control target is to obtain smooth active and reactive power output by choosing $P_{g}$ and $Q_{g}$ as the input signal of VPI controller. $\Delta u_{c d}^{+}$and $\Delta u_{c q}^{+}$are the voltage compensation parts and can be depicted as,

$$
\left\{\begin{array}{l}
\Delta u_{c d}^{+}=\frac{2}{3} \frac{\omega_{g} L}{U_{g d}^{+}} Q_{g} \\
\Delta u_{c q}^{+}=\frac{2}{3} \frac{\omega_{g} L}{U_{g d}^{+}} P_{g}
\end{array}\right.
$$

\section{VPI Controller}

When target (2) of smooth active and reactive power is chosen, the scheme of the proposed DPC in (dq)+ 
fundamental synchronous frame can be shown in Fig. 4. The closed loop transfer function can be expressed as

$$
\frac{S_{g}}{S_{g}^{*}}=\frac{G_{P I}(s)}{G_{P I}(s)+G_{V P I}(s)-(L s+R) / U_{g d}^{+}}
$$

where $G_{P I}(s)$ is the transfer function of PI regulator and $G_{V P I}(s)$ is the transfer function of VPI regulator.

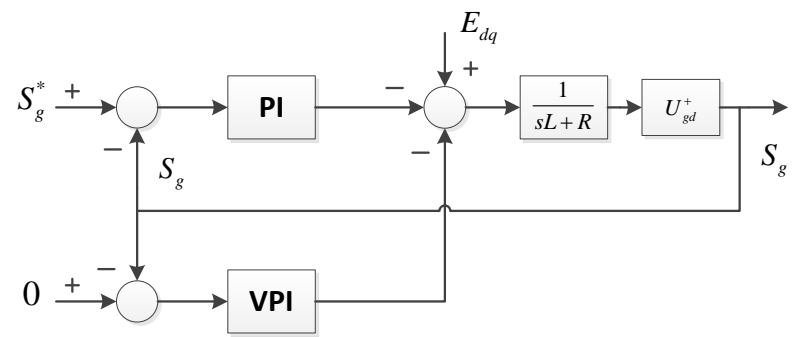

Fig. 4 The control scheme for target of smooth active/ reactive power

According to traditional voltage oriented vector control mathematic model of VSC, the power can be written as

$$
\left\{\begin{array}{l}
P_{g}=\frac{3}{2} U_{g d}^{+} I_{g d}^{+} \\
Q_{g}=-\frac{3}{2} U_{g d}^{+} I_{g q}^{+}
\end{array}\right.
$$

Substituting (16) into (15), the control loop transfer function under target of balanced and sinusoidal current can be written as (17). And Fig. 5 shows the scheme of the proposed DPC for the balanced and sinusoidal current.

$$
\frac{I_{g}}{I_{g}^{*}}=\frac{G_{P I}(s)}{G_{P I}(s)+G_{V P I}(s)-(L s+R)}
$$

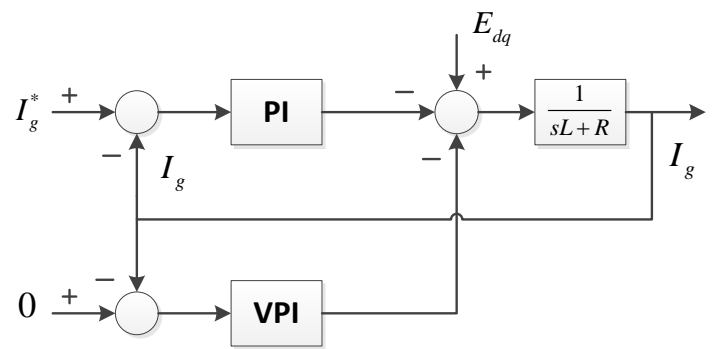

Fig. 5 The control scheme for target of balanced and sinusoidal current

The basic open-loop transfer function of VPI can be derived from the conventional PI controller. Considering the bandwidths at the resonant frequency, the transfer function of VPI for $\mathrm{k}^{\text {th }}$ harmonic component can be expressed as following [13]-[14],

$$
G_{V P I}(s)=\frac{K_{p k} s^{2}+K_{i k} s}{s^{2}+\omega_{c k} s+\left( \pm k \omega_{g}\right)^{2}}
$$

where $\omega_{\mathrm{c}}$ represents the cutoff frequency to broaden the frequency bandwidth.

When VSI is controlled under the unbalanced and harmonic voltage conditions, the resonant frequency of VPI controller should be tuned at the twice and sixth fundamental frequency. Thus, the whole transfer function of VPI controllers can be expressed as

$$
G_{V P I}(s)=\frac{K_{p 2} s^{2}+K_{i 2} s}{s^{2}+\omega_{c 2} s+\left( \pm 2 \omega_{g}\right)^{2}}+\frac{K_{p 6} s^{2}+K_{i 6} s}{s^{2}+\omega_{c 6} s+\left( \pm 6 \omega_{g}\right)^{2}}
$$

Compared with conventional DPC strategy, DPC with VPI regulator with $2 \omega_{\mathrm{g}}$ and $6 \omega_{\mathrm{g}}$ resonant radians frequency can avoid the sequential decomposition of both negative, $5^{\text {th }}$ and $7^{\text {th }}$ harmonic components of grid voltages and currents. Thus, the fast dynamic response and stable close-loop operation can be achieved for different control targets.

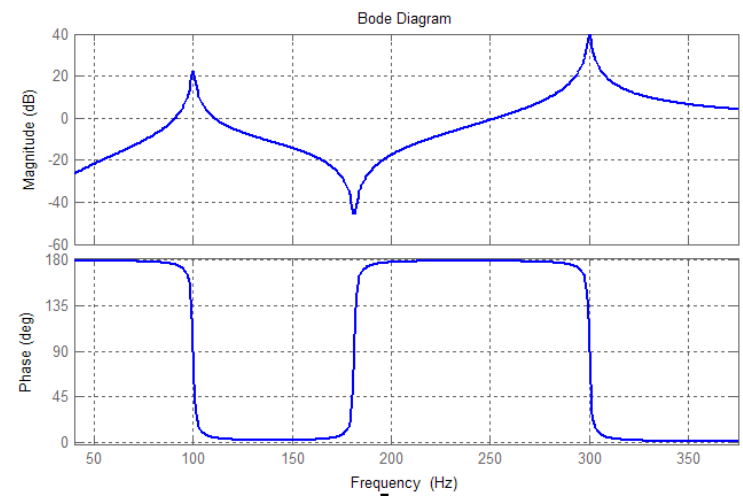

Fig. 6 Bode diagram of VPI regulators with resonant frequency at $100 \mathrm{~Hz}$ and $300 \mathrm{~Hz}\left(\omega_{c 2}=\omega_{c 6}=10 \mathrm{rad} / \mathrm{s}\right.$, $\omega_{\mathrm{g}}=100 \pi \mathrm{rad} / \mathrm{s}, k_{p r 2}=0.2, k_{p r 6}=0.5, k_{i r 2}=3.14 k_{p r 2}$, $\left.k_{i r 6}=3.14 k_{p r 6}\right)$

The bode diagram of open-loop transfer function of VPI regulator is showed in Fig. 6. The phase margin at each resonant frequency would be a sufficiently large of $92.8^{\circ}$ and $123^{\circ}$, which means that the stable operation of VSI under the unbalanced and harmonic grid condition can be implemented.

The open loop transfer function of the VPI controller at special resonant frequency of DPC strategy is showed as

$$
G_{o l}(s)=G_{V P I}(s) * G_{p l a n t}(s) * U_{g d}^{+}
$$

where $G_{\text {plant }}(s)=1 /(s L+R)$. 
Since $U_{g d}^{+}$can be approximate to unit, the closed loop transfer function of the VPI controller of the proposed DPC strategy can be written as

$$
G_{c l}(s)=G_{V P I}(s) * G_{\text {plant }}(s) /\left(1+G_{V P I}(s) * G_{\text {plant }}(s)\right)
$$

The bode diagram of the harmonic control closed-loop transfer function is showed in Fig. 7. At the resonant frequency of $100 \mathrm{~Hz}$ and $300 \mathrm{~Hz}$, the phase respond is $0^{\circ}$ and the magnitude respond is $0 \mathrm{~dB}$, which can ensure the accurate tracking of ac signal to fulfill specific control targets.

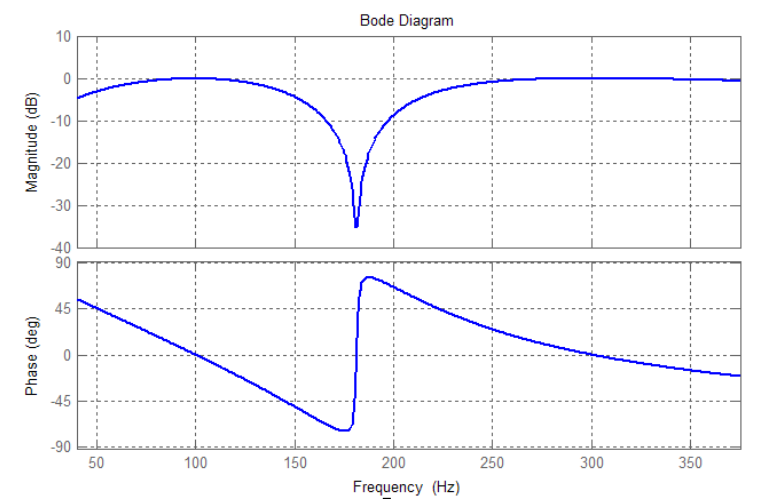

Fig. 7 Bode diagram of harmonic control closed-loop with resonant frequency $100 \mathrm{~Hz}$ and $300 \mathrm{~Hz}$ $\left(\omega_{c 2}=\omega_{c 6}=10 \mathrm{rad} / \mathrm{s}, \omega_{\mathrm{g}}=100 \pi \mathrm{rad} / \mathrm{s}, k_{p r 2}=0.2, k_{p r 6}=0.5\right.$, $k_{i r 2}=3.14 k_{p r 2}, \quad k_{i r 6}=3.14 \quad k_{p r 6}, R=8.3317 e-04$, $L=2.6520 e-04$ )

\section{Simulation Results}

The Simulation studies on a $2 \mathrm{MW}$ rated grid-connected voltage-sourced converter under grid unbalanced conditions have been implemented by MATLAB/Simulink. The simulation system is sampled at a frequency of $5 \mathrm{kHz}$ and the switching frequency is $2.5 \mathrm{kHz}$. Grid voltage is $690 \mathrm{~V}$ and the system is supplied by a DC voltage of $1200 \mathrm{~V}$. Line inductance is $0.265 \mathrm{mH}$. Line resistor is $0.8 \Omega$. In the simulation, the unbalance of grid voltage is initially set to $10 \%$ and the grid voltage is initially injected with $7 \%$ th and $7 \%$ 7th order harmonic components.

Fig. 8 shows the simulation results of VSI system by the proposed DPC strategy. The control target is set to target 1 for balanced and sinusoidal current from $0.05 \mathrm{~s}$ to $0.15 \mathrm{~s}$, and target 2 for obtaining smooth active/reactive power from $0.15 \mathrm{~s}$ to $0.25 \mathrm{~s}$. From $0.25 \mathrm{~s}$ to $0.3 \mathrm{~s}$, the grid voltage becomes ideal. During target 1), the output current of the inverter can be controlled with THD $1.58 \%$. The active/reactive power ripple with VPI controller from $0.15 \mathrm{~s}$ to $0.25 \mathrm{~s}$ is $\pm 0.02 \mathrm{pu}$, which is the same as the results under ideal grid condition.
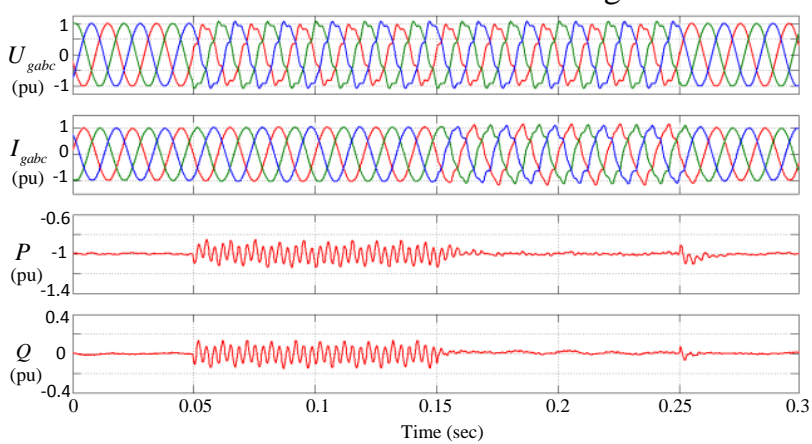

Fig. 8 Simulation results of VSI system under the unbalanced and harmonic grid voltage condition

Fig. 9 shows the simulation result with the control target of the balanced and sinusoidal current, in which the active power reference steps from $-1 \mathrm{pu}$ to $-0.5 \mathrm{pu}$ at $0.1 \mathrm{~s}$ and the active power reference steps from $-0.5 \mathrm{pu}$ to $-1 \mathrm{pu}$ at $0.3 \mathrm{~s}$. It can be seen that the current of VSI can keep sinusoidal under the power change condition with the proposed DPC strategy.

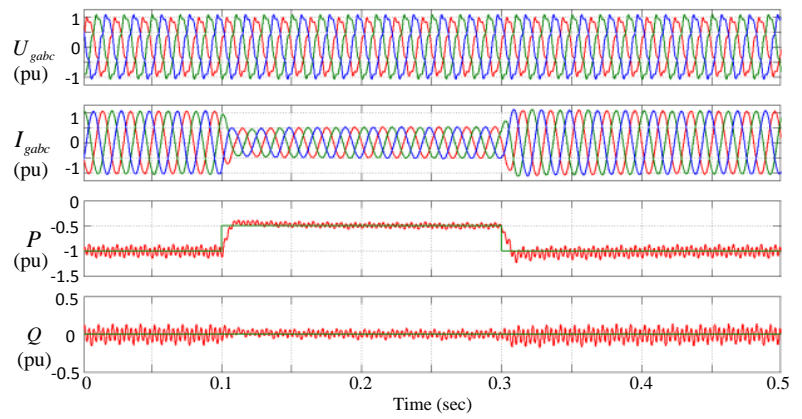

Fig. 9 Simulation results of VSI system with target of balanced and sinusoidal current.

Fig. 10 shows the simulation results with the control target of the smooth active/reactive power, in which the active power reference steps from - $1 \mathrm{pu}$ to $-0.5 \mathrm{pu}$ at $0.1 \mathrm{~s}$, the reactive power reference steps from $0 \mathrm{pu}$ to $-0.2 \mathrm{pu}$ at $0.2 \mathrm{~s}$, the active power reference steps from -0.5 to -1 at $0.3 \mathrm{~s}$ and the reactive power reference steps from -0.2 to 0 at $0.4 \mathrm{~s}$. It can be seen that, although there is a little overshoot of the actual power on the power step change, the output active and reactive power can keep stable on the steady state.

Fig. 11. and 12. shows the simulation result of VSI for the control target 1 and 2 when the harmonic components vary. It can be seen that, even if the grid condition changes, the control target can still be achieved with the satisfied steady and dynamic performance by the proposed DPC strategy. However, the power fluctuations are related with the grid voltage and output current phase difference. Thus, the variations of active power and reactive power are un- 
uniform.

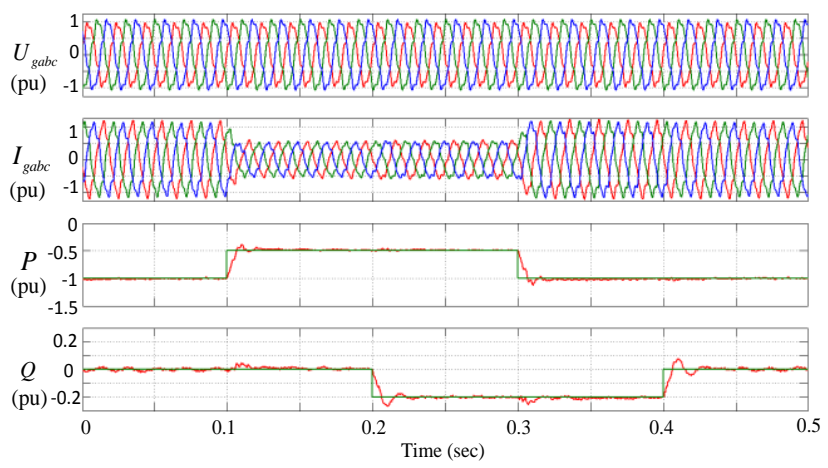

Fig. 10 Simulation results of VSI system with target of smooth active and reactive power.

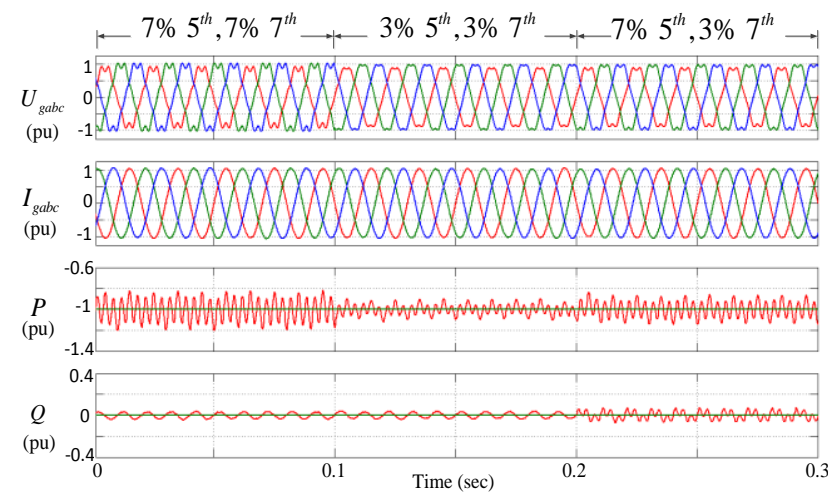

Fig. 11 Simulation results of VSI system under $10 \%$ unbalanced, variable harmonic grid voltage condition with target 1

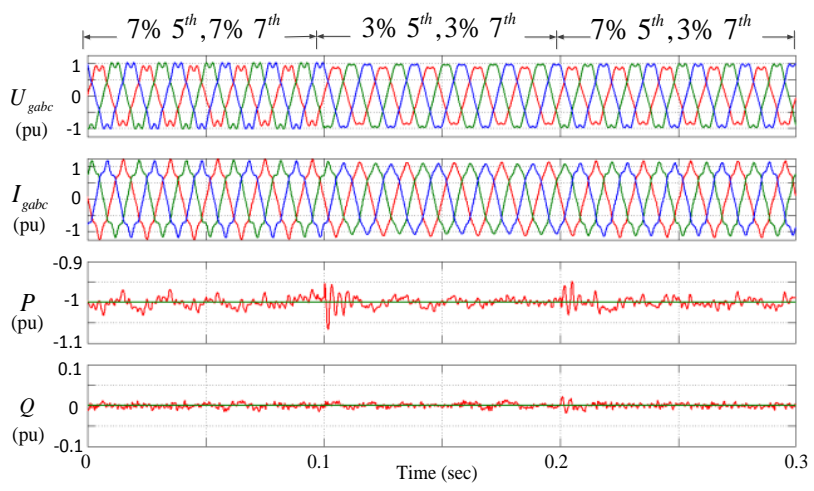

Fig. 12 Simulation results of VSI system under $10 \%$ unbalanced, variable harmonic grid voltage condition with target 2

\section{Conclusion}

This paper proposed an improved DPC strategy for VSI under unbalanced and harmonic distorted grid voltage conditions. The improved DPC can achieve two control targets of different concerns, 1) balanced and sinusoidal ac- side current; 2) smooth ac-side active and reactive power. The complicated control reference calculation and sequence decomposition is not needed in the proposed DPC strategy. Simulation results validated the improved DPC availability with the VPI controller under the unbalanced and harmonic grid conditions.

\section{References}

[1] J. M. Carrasco, L. G. Franquelo, J. T. Bialasiewicz, E. Galvan, R. C.P. Guisado, Ma. A. M Prats, J. I. Leon, and N. MorenoAlfonso, "Power electronic systems for the grid integration of renewable energy sources: A survey," IEEE Transactions on Industrial Electronics, vol. 53, no. 4, pp. 1002-1016, Jun. 2006.

[2] M.Malinowski, M. P. Kazmierkowski, and A. M. Trzynadlowski, "A comparative study of control techniques for PWM rectifiers in AC adjustable speed drives," IEEE Transactions on Power Electronics, vol. 18, no. 6, pp. 13901396, Nov. 2003.

[3] Zhi, D, Xu, L. "Improved direct power control of gridconnected DC AC converters," IEEE Transactions on Power Electronics, vol. 24, no. 5, pp. 1280-1292, 2009.

[4] Lohde, R. and F.W. Fuchs., "Improved DPC method of VSC to fulfill low voltage ride through requirements in wind power applications," Proc. of 14th International Power Electronics and Motion Control Conference (EPE/PEMC 2010), pp. 1235-1242, 2010.

[5] Eloy-Garcia, J., S. Arnaltes and J.L. Rodriguez-Amenedo, "Direct power control of voltage source inverters with unbalanced grid voltages," IET on Power Electronics, pp. 395-407, 2008.

[6] Yu Quan, Heng Nian, Jiabing Hu and Jiawen Li, "Improved control of the grid-connected converter under the harmonically distorted grid voltage," Proc. of 2010 International Conference Electrical Machines and Systems (ICEMS 2010), pp. $204-209,2010$.

[7] Hong-Seok, S. and N. Kwanghee, "Dual current control scheme for PWM converter under unbalanced input voltage conditions", IEEE Transactions on Industrial Electronics, vol.46, no.5, pp. 953-959, 1999.

[8] Yongsug, S. and T.A. Lipo, "Control scheme in hybrid synchronous stationary frame for PWM AC/DC converter under generalized unbalanced operating conditions," IEEE Transactions on Industry Applications, vol. 42, no. 3, pp. 825-835, 2006.

[9] Hailiang, X., H. Jiabing and H. Yikang, "Integrated modeling and enhanced control of DFIG under unbalanced and distorted grid voltage conditions," IEEE Transactions on Energy Conversion, vol. 27, no. 3, pp.725-736, 2012.

[10] Peng, Z., Yikang H. and Dan S., "Improved direct power control of a DFIG-based wind turbine during network unbalance," IEEE Transactions on Power Electronics, vol. 24 no. 11 , pp. 2465-2474, 2009.

[11] Malinowski, M., Jasinski M. and Kazmierkowski M.P., "Simple direct power control of three-phase PWM rectifier using space-vector modulation (DPC-SVM)," IEEE Transactions on Industrial Electronics, vol. 51, no. 2, pp. 447-454, 2004.

[12] Lei S, "Predictive direct power control of grid-connected voltage-sourced converters under unbalanced grid voltage conditions," Proc. of 2009 International Conference 
Electrical Machines and Systems (ICEMS 2009), pp. 1-5, 2009.

[13] Cristian Lascu, Lucian Asiminoaei, Ion Boldea and Frede Blaabjerg, "High performance current controller for selective harmonic compensation in active power filters," IEEE Transactions on Power Electronics, vol. 22, no. 5, pp. 18261835, Sep. 2007.

[14] Cristian Lascu, Lucian Asiminoaei, Ion Boldea and Frede Blaabjerg, "Frequency response analysis of current controllers for selective harmonic compensation in active power filters," IEEE Transactions on Industrial Electronics, vol. 56, no. 2, pp. 337-347, Feb. 2009.

[15] A. G. Yepes, F. D. Freijedo, J. Doval-Gandoy, O. Lopez, J. Malvar, and P. Fernandez-Comesana, "Etfects of discretization methods on the performance of resonant controllers," IEEE Transactions on Power Electronics, vol. 25, no. 7, pp. 1692-1712, Jul. 2011

[16] Vidal, A.; Freijedo, F. D.; Yepes, A. G., “Transient response assessment of vector PI current controllers in renewable energy applications," Proc. in 38th Annual Conference on IEEE Industrial Electronics Society (IECON 2012), 2012.

[17] Reyes, M., et al, "Enhanced decoupled double synchronous reference frame current controller for unbalanced gridvoltage conditions," IEEE Transactions on Power Electronics, vol. 27, no. 9, pp. 3934-3943, 2012.

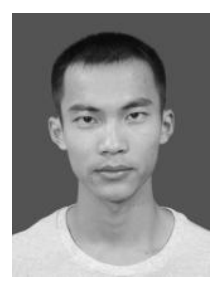

Yongbo Shen received his B.E degree in electrical engineering from Zhejiang University. His research interests are grid connected inverters in the distributed generation energy systems.

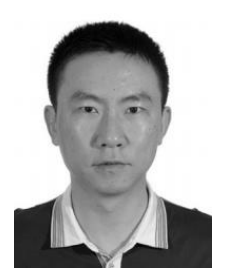

Heng Nian received his $\mathrm{Ph} . \mathrm{D}$ degree from Zhejiang University. $\mathrm{He}$ has been an Associate Professor since 2007. His current research interests are the topology and control of DGs. 